\title{
Safety of dual biological therapy in Crohn's disease: a case series of vedolizumab in combination with other biologics
}

\author{
Eric J Mao, ${ }^{1}$ Sara Lewin, ${ }^{2}$ Jonathan $\mathrm{P}$ Terdiman, ${ }^{2}$ Kendall Beck ${ }^{2}$
}

\begin{abstract}
Uncertainty exists regarding safety and efficacy of dual biological therapy (DBT) in inflammatory bowel disease. We present four cases of DBT in Crohn's disease. Three patients had refractory disease non-responsive to biological monotherapy or combination therapy with immunomodulators. One patient had concomitant ankylosing spondylitis. DBT was implemented by combining vedolizumab with an anti tumour necrosis antibody or with ustekinumab. DBT was well-tolerated, though two patients did experience self-limited infections. The efficacy of DBT remains unproven but it appears promising as three of the four patients achieved clinical remission. Our case series contributes insight into the safety of DBT that incorporates vedolizumab for future efficacy studies.
\end{abstract}

\section{INTRODUCTION}

Biologics are the mainstay of therapy in inflammatory bowel disease (IBD), rheumatological disease and dermatological disease. The safety profile of biological monotherapy or in combination with immunomodulators has been well-characterised. ${ }^{1}$ There have been a few prior reports of the use of dual biological therapy (DBT) for refractory IBD and in patients with a dual diagnosis of IBD and other immune-mediated inflammatory disease. ${ }^{2-9}$ DBT has also been explored in both the rheumatological and dermatological literature, but the biologics used differ from those used in IBD. ${ }^{10}$ To contribute further understanding on DBT in IBD, we present a case series of four patients with Crohn's disease (CD) treated with DBT.

\section{CASE REPORTS}

The first case is a young man diagnosed with ileocolonic $\mathrm{CD}$ and ankylosing spondylitis (AS) at age 13. His index upper endoscopy and colonoscopy revealed esophagitis and ileitis. His CD had been treated unsuccessfully with mesalamine preparations, 6-mercaptopurine (6-MP) monotherapy, subcutaneous methotrexate monotherapy and infliximab. He remained steroid dependent despite these therapies. He was able to achieve a steroid-free clinical remission in his CD with adalimumab monotherapy. His AS was quiescent with adalimumab as well. Unfortunately, he had several lapses in adalimumab therapy leading to drug antibody formation and secondary loss of response. He was subsequently started on vedolizumab $300 \mathrm{mg}$ every 8 weeks and azathioprine $50 \mathrm{mg}$ daily with clinical response. A repeat colonoscopy and endoscopy showed persistent terminal ileitis, prompting escalation of vedolizumab dosing to every 4 weeks. On transition from adalimumab to vedolizumab, the patient noted worsening of AS symptoms of back and hip pain. He was hospitalised for a flare of his AS 1 year after transitioning to vedolizumab. MRI revealed severe hip inflammatory arthropathy bilaterally with sacroiliac joint fusion. Given the prior clinical response of his AS to antitumour necrosis factor therapy (anti-TNF), etanercept $50 \mathrm{mg}$ weekly was added to vedolizumab and azathioprine. The azathioprine was discontinued 3 months afterwards due to concern for excessive immunosuppression. Within 3 months of initiation of etanercept, his joint pains were well controlled. After 20 months on DBT without severe adverse events or infectious complications (table 1), his AS remained quiescent, but his CD flared despite vedolizumab and prednisone $60 \mathrm{mg}$ daily. His laboratory tests demonstrated elevated $\mathrm{C}$ reactive protein (CRP) of $20.5 \mathrm{mg} / \mathrm{L}$, erythrocyte sedimentation rate (ESR) of 77 of $\mathrm{mm} /$ hour, albumin of $3.3 \mathrm{~g} / \mathrm{dL}$ and vedolizumab trough drug level of $12 \mu \mathrm{g} / \mathrm{mL}$ without antibodies. A limited colonoscopy revealed multiple deep, serpiginous ulcers in the sigmoid colon with histology confirming chronic active colitis. In collaboration with rheumatology, etanercept 
Table 1 Safety experience of dual biological therapy in Crohn's disease

\begin{tabular}{|c|c|c|c|c|c|}
\hline Case & Disease & Dual biological regimen & $\begin{array}{l}\text { Duration of } \\
\text { dual biological } \\
\text { therapy }\end{array}$ & Adverse events & $\begin{array}{l}\text { Crohn's disease } \\
\text { status }\end{array}$ \\
\hline \multirow[t]{2}{*}{1} & \multirow{2}{*}{$\begin{array}{l}\text { lleocolonic Crohn's disease, ankylosing } \\
\text { spondylitis }\end{array}$} & Etanercept and vedolizumab & 20 months & None & \multirow[t]{2}{*}{ Active } \\
\hline & & Etanercept and ustekinumab & 2 months & None & \\
\hline 2 & Colonic and perianal Crohn's disease & Vedolizumab and ustekinumab & 5 months & $\begin{array}{l}\text { Two Clostridium } \\
\text { difficile infections }\end{array}$ & Clinical remission \\
\hline 3 & $\begin{array}{l}\text { lleocolonic and perianal Crohn's } \\
\text { disease }\end{array}$ & Vedolizumab and golimumab & 8 months & None & Clinical remission \\
\hline 4 & $\begin{array}{l}\text { Ileocolonic and perianal Crohn's } \\
\text { disease }\end{array}$ & $\begin{array}{l}\text { Vedolizumab, golimumab and } \\
6 \text {-mercaptopurine }\end{array}$ & 37 months & $\begin{array}{l}\text { Hand-foot-mouth } \\
\text { disease and influenza }\end{array}$ & Clinical remission \\
\hline
\end{tabular}

was continued to maintain AS remission and vedolizumab was switched to ustekinumab with the addition of methotrexate. He remains symptomatic from a $\mathrm{CD}$ perspective after receiving ustekinumab induction, though with good control of joint pains.

Comment: This case illustrates a situation where combining rather than switching biologics is the most practical approach to effectively treat both diseases. Unfortunately, DBT did not maintain remission for both conditions and he required another biological switch in an attempt to effectively manage his CD. The efficacy of DBT remains unproven but combination of anti-TNF and vedolizumab appeared to be safe and well-tolerated in this case.

The second case is a young man diagnosed with colonic and perianal $\mathrm{CD}$ at age 12 . He had been treated unsuccessfully with $4.8 \mathrm{~g}$ of mesalamine, requiring intermittent courses of prednisone $40 \mathrm{mg}$ daily with taper. He achieved clinical remission for 5 years with infliximab $5 \mathrm{mg} / \mathrm{kg}$ administered every 8 weeks and subcutaneous methotrexate $25 \mathrm{mg}$ weekly. But, he experienced a secondary loss of response due to mechanistic failure despite increasing the infliximab dose to $10 \mathrm{mg} / \mathrm{kg}$ administered every 8 weeks. At this time, his faecal calprotectin was $1362 \mu \mathrm{g} / \mathrm{g}$, and colonoscopy demonstrated colitis to the hepatic flexure with biopsies confirming active colitis throughout. He had an infliximab drug trough level of $31.2 \mu \mathrm{g} / \mathrm{mL}$ without antibodies. Biologics was switched to ustekinumab $90 \mathrm{mg}$ subcutaneous every 8 weeks and subcutaneous weekly methotrexate was continued. Initially, the patient demonstrated a clinical response to ustekinumab, but persistent symptoms led to escalation of ustekinumab administration to every 4 weeks. Unfortunately, he continued to experience bloody diarrhoea and nocturnal symptoms, requiring concurrent high-dose prednisone taper. His laboratories demonstrated a CRP of $40.9 \mathrm{mg} / \mathrm{L}$ and albumin of $3.5 \mathrm{~g}$ / dL. Given his partial response to ustekinumab and prior mechanistic failure of anti-TNF, vedolizumab $300 \mathrm{mg}$ induction followed by maintenance every 8 weeks was added to ustekinumab. After initiation of vedolizumab, ustekinumab dose was de-escalated to every 8 weeks. After 2 months of DBT with vedolizumab and ustekinumab every 8 weeks, he achieved steroid-free clinical remission. During 5 months of DBT, he experienced two episodes of Clostridium difficile infection (CDI) that resolved with 2 week courses of vancomycin.

Comment: In a patient with severely active disease and limited alternative biological therapies, this case demonstrates the efficacy of DBT to achieve clinical remission. Although he developed CDI shortly after DBT initiation, he possessed many CDI risk factors including high-dose steroids and severe IBD. Ultimately, the possibility of achieving clinical remission outweighed potential adverse effects of DBT, especially with the favourable safety profiles of vedolizumab and ustekinumab.

The third case is a young man with stricturing ileocolonic and perianal CD diagnosed at age 6. He was initially treated with mesalamine, azathioprine and budesonide. At age 12, he started infliximab and azathioprine combination therapy. Despite combination therapy, at age 14, he developed multiple small and large bowel obstructions, requiring ileal resection and right hemicolectomy with primary ileocolonic anastomosis. Postoperatively, he was not on therapy. He developed disease recurrence at age 18 and failed to respond to adalimumab, certolizumab and ustekinumab. He did not tolerate methotrexate or tofacitinib. At age 23, he required another ileocolonic resection with end-ileostomy. Postoperatively, vedolizumab $300 \mathrm{mg}$ every 8 weeks was started but he experienced disease recurrence 1 year after initiation. Magnetic resonance enterography demonstrated inflammatory changes and narrowing in two segments of small bowel. At age 26, the patient was admitted to the hospital with a partial small bowel obstruction requiring intravenous corticosteroids, despite vedolizumab dose intensification to every 4 weeks. Laboratory studies during this hospitalisation demonstrated a serum albumin $3.3 \mathrm{~g} / \mathrm{dL}$, ESR $15 \mathrm{~mm} / \mathrm{h}$, CRP $41.2 \mathrm{mg} / \mathrm{L}$ and an elevated faecal calprotectin $1407.5 \mathrm{mcg} / \mathrm{g}$. CT of the abdomen and pelvis with contrast demonstrated focal ileal luminal narrowing with proximal bowel dilatation and mid jejunal wall thickening with mild hyperenhancement with proximal bowel dilatation. In addition to a prednisone taper, golimumab $100 \mathrm{mg}$ subcutaneously every 28 days was then added to his regimen given his reluctance to pursue further surgery. During 8 months of DBT, he developed one flare of partial small bowel obstruction requiring hospitalisation and corticosteroids. He has successfully tapered off 
of corticosteroids and considers himself in clinical remission with most recent laboratory studies demonstrating albumin $4.1 \mathrm{~g} / \mathrm{dL}$, ESR $2 \mathrm{~mm} / \mathrm{h}$ and CRP $4.7 \mathrm{mg} / \mathrm{L}$. He has not experienced infectious complications.

Comment: DBT was pursued as a surgery-sparing strategy in severe $\mathrm{CD}$. He did experience a flare of his $\mathrm{CD}$ while on DBT, but he is now in clinical and biochemical remission and the regimen of anti-TNF and vedolizumab seems to be well-tolerated.

The final case is a young woman with stricturing ileocolonic and perianal CD diagnosed at age 14. She initially failed infliximab $5 \mathrm{mg} / \mathrm{kg}$ every 8 weeks, adalimumab 40 mg subcutaneous weekly and certolizumab $400 \mathrm{mg}$ subcutaneous every 4 weeks, leading to ileocolic resection. Postoperatively, she achieved clinical remission on natalizumab $300 \mathrm{mg}$ infused every 4 weeks but developed antibodies to the John Cunningham virus and the drug was stopped. She subsequently flared, and unfortunately failed ustekinumab $90 \mathrm{mg}$ subcutaneous (without intravenous induction dosing) in addition to methotrexate $25 \mathrm{mg}$ subcutaneous weekly. Colonoscopy at this time demonstrated mild to moderate colitis in the rectum and sigmoid colon, ileal stricture and moderate to severe ileitis. She required a second ileal resection with diverting loop ileostomy for severe perianal disease, which was complicated by postoperative recurrence only 8 weeks after surgery, with laboratory values including CRP of $33.9 \mathrm{mg} / \mathrm{L}$ and albumin of $2.5 \mathrm{~g} / \mathrm{dL}$, confirmed by ileoscopy demonstrating distal ileal and stomal ulcerations. After failing a trial of oral tacrolimus and tocilizumab (anti-interleukin 6), she started tofacitinib $10 \mathrm{mg}$ oral two times a day and methotrexate 25 mg subcutaneous once a week along with several months of total parenteral nutrition. This regimen induced a partial symptomatic and endoscopic response with significant healing of the ileitis, prompting eventual reversal of the ileostomy. This response was then lost following drug discontinuation for spinal surgery for herniated lumbar disc with neurological compromise. Given prior response to natalizumab, vedolizumab $300 \mathrm{mg}$ infused every 4 weeks was initiated in June 2014 after ileostomy takedown. Tofacitinib $10 \mathrm{mg}$ oral two times a day and 6-MP $75 \mathrm{mg}$ oral once a day were added with good clinical response. Tofacitinib was subsequently discontinued and switched to golimumab $100 \mathrm{mg}$ subcutaneous every 2 weeks in May 2015 as the patient desired conception. She achieved clinical remission on this regimen, though this has not been confirmed endoscopically. Her first pregnancy was uncomplicated and the baby was delivered at term on golimumab $100 \mathrm{mg}$ subcutaneous every 2 weeks, vedolizumab $300 \mathrm{mg}$ intravenous every 4 weeks and 6-MP $75 \mathrm{mg}$ oral once a day. Her second pregnancy, on the same medical regimen, was complicated by subchorionic haemorrhage and single umbilical artery, hand-foot-mouth disease that self-resolved and influenza despite vaccination. Her perianal disease transiently worsened and was managed effectively with metronidazole and topical tacrolimus. She delivered another normal baby at term.
Comment: In a patient with CD with limited therapeutic options after failing multiple biological therapies, DBT enabled her to achieve clinical remission and pursue pregnancy. Although she experienced self-limited viral illnesses, she has not had any serious infectious complications after 3 years of DBT.

\section{DISCUSSION}

These cases illustrate the complexities in managing patients with $\mathrm{CD}$ who have failed multiple prior biologics or have comorbid immune-mediated inflammatory conditions. It is difficult to abandon biological therapy that is effective for coexisting non-IBD conditions or partially effective for IBD. These four patients tolerated DBT without serious adverse events. One patient has tolerated DBT for greater than 3 years. These cases support the safety of vedolizumab-based DBT, and efficacy appears promising with three of four patients achieving clinical remission in our series. Larger studies are necessary to investigate the safety and efficacy of DBT. There is insufficient literature to support DBT as routine practice, but it may become a viable therapeutic approach to treat complex and severe IBD without sacrificing safety. Our case series provides a foundation for future studies to explore the safety and efficacy of DBT.

Contributors EJM, SL, JPT and KB all participated in the planning and writing of this case series. EJM and KB are the contributors who are responsible for the overall content as guarantors.

Funding The authors have not declared a specific grant for this research from any funding agency in the public, commercial or not-for-profit sectors.

Competing interests None declared.

Patient consent Not required.

Provenance and peer review Not commissioned; externally peer reviewed

Author note EJM changed affiliations from University of California, San Francisco to University of California, Davis during the project.

Open access This is an open access article distributed in accordance with the Creative Commons Attribution Non Commercial (CC BY-NC 4.0) license, which permits others to distribute, remix, adapt, build upon this work non-commercially, and license their derivative works on different terms, provided the original work is properly cited, appropriate credit is given, any changes made indicated, and the use is non-commercial. See: http://creativecommons.org/licenses/by-nc/4.0

\section{REFERENCES}

1. Bonovas S, Fiorino G, Allocca M, et al. Biologic therapies and risk of infection and malignancy in patients with inflammatory bowel disease: a systematic review and network meta-analysis. Clin Gastroenterol Hepatol 2016;14:1385-97.

2. Yzet C, Dupas JL, Fumery M. Ustekinumab and anti-TNF combination therapy in patients with inflammatory bowel disease. Am J Gastroenterol 2016;111:748-9.

3. Sands BE, Kozarek R, Spainhour J, et al. Safety and tolerability of concurrent natalizumab treatment for patients with Crohn's disease not in remission while receiving infliximab. Inflamm Bowel Dis 2007;13:2-11.

4. Hirten R, Longman RS, Bosworth BP, et al. Vedolizumab and infliximab combination therapy in the treatment of crohn's disease. Am J Gastroenterol 2015;110:1737-8.

5. Christensen B, Gibson P, Micic D, et al. Safety and efficacy of combination treatment with calcineurin inhibitors and vedolizumab in patients with refractory inflammatory bowel disease. Clin Gastroenterol Hepatol 2018. 
6. Buer LCT, Høivik ML, Warren DJ, et al. Combining anti-TNF- $\alpha$ and vedolizumab in the treatment of inflammatory bowel disease: a case series. Inflamm Bowel Dis 2018;24:997-1004.

7. Roblin X, Paul S, Ben-Horin S. Co-treatment with golimumab and vedolizumab to treat severe $\mathrm{UC}$ and associated spondyloarthropathy. J Crohns Colitis 2018;12:379-80.

8. Bethge J, Meffert S, Ellrichmann M, et al. Combination therapy with vedolizumab and etanercept in a patient with pouchitis and spondylarthritis. BMJ Open Gastroenterol 2017;4:e000127.

9. Liu EY, Loomes DE. Ustekinumab and Vedolizumab Dual Biologic Therapy in the Treatment of Crohn's Disease. Case Rep Med 2017;2017:1-2.

10. Hirten RP, lacucci M, Shah $\mathrm{S}$, et al. Combining biologics in inflammatory bowel disease and other immune mediated inflammatory disorders. Clin Gastroenterol Hepatol 2018;16:1374-84. 